\title{
Artigo
}

\section{Preparando o caminho para a paz? O uso da força em Operações de paz das Nações Unidas ${ }^{1}$}

\section{Preparing the road to Peace? The use of force in United Nations Peace Operations}

Laura Meneghim Donadelli

Leonardo Dias de Paula ${ }^{3}$

DOI: 10.5752/P.1809-6182.2018v15.n3.p6

Recebido em: 09 de dezembro de 2018 Aprovado em: 18 de março de 2019

\begin{abstract}
Resumo
A ampliação das prerrogativas para o uso da força em Operaçóes de Paz da Organização das Naçôes Unidas implicou novos obstáculos à manutenção da paz. No presente texto, exploramos a progressiva aproximação desde a década de 1990 entre essas operaçóes e o engajamento das potências internacionais em conflitos assimétricos.
\end{abstract}

Palavras-chave: Operaçôes de Paz; Organização das Naçōes Unidas; Uso da Força.

\begin{abstract}
The broadening of the prerogatives for the use of force in United Nations Peace Operations has created new obstacles for the consolidation of peace. In the current article, we explore the progressive approximation between such operations and the engagement of international powers in asymmetrical conflicts.
\end{abstract}

Keywords: Peace Operations; United Nations Organization; Use of Force

1. O presente trabalho foi realizado com apoio da Coordenação de Aperfeiçoamento de Pessoal de Nível Superior Brasil (CAPES) - Código de Financiamento 001.

2. Doutoranda pelo Programa de Pós-graduação em Relaçóes Internacionais San Tiago Dantas (UNESP, UNICAMP, PUC/SP). Bolsista da Coordenação de Aperfeiçoamento de Pessoal de Nível Superior (CAPES). Mestre em Relaçôes Internacionais pela mesma instituição e graduada pela Universidade Estadual Paulista (UNESP). Membro do Grupo de Estudos em Defesa e Segurança Internacional (GEDES) e do Observatório Sul-americano de Defesa e Forças Armadas. São Paulo, Brasil. ORCID 0000-0003-2468-2221.

3. Mestrando pelo Programa de Pós-graduação em Relações Internacionais San Tiago Dantas (UNESP, UNICAMP, PUC/SP). Bolsista da Coordenação de Aperfeiçoamento de Pessoal de Nível Superior (CAPES). Graduado em Relações Internacionais pela Universidade Estadual Paulista (UNESP). Membro do Grupo de Estudos em Defesa e Segurança Internacional (GEDES) e do Observatório Sul-americano de Defesa e Forças Armadas. São Paulo, Brasil. ORCID 0000-0003-1585-6269. 


\section{Introdução}

Tradicionalmente, as operaçóes de paz aprovadas pelo Conselho de Segurança das Naçôes Unidas (CSNU) apresentaram mandatos que limitavam o recurso a meios coercitivos à defesa do pessoal e instalações mobilizadas. No entanto, é possível observar o acúmulo de tensões favoráveis à expansão da disponibilidade de recursos bélicos robustos e à autorização para engajamento preemptivo contra atores relevantes como alternativa para as iniciativas de resolução dos conflitos sob intervenção internacional. Os marcos de revisão dos princípios doutrinários indicaram uma tendência à intensificação do recurso à violência em operaçôes de paz. Ressaltamos, no entanto, que a construção da paz depende de dinâmicas que divergem da práxis da resolução bélica, pautada em necessidades identificadas pela comunidade local em relação à possibilidade de manter relaçóes não-violentas.

No presente texto pretendemos examinar as transformaçōes na interpretação institucional sobre o emprego da força em operações de paz da Organização da Nações Unidas (ONU). Argumentamos que o engajamento mais ofensivo de soldados internacionais consiste em uma tendência das operaçóes de paz aprovadas pelo CSNU que se acentuou significativamente através de um esforço de reforma doutrinária iniciado após os resultados controversos de intervenções mobilizadas sob a égide da ONU durante a década de 1990. Ademais, é plausível indicar que a atuação do componente militar dessas operaçóes tende a se aproximar da performance de outras campanhas militares em conflitos assimétricos. Para tanto, recuperamos textos da instituição que indicam interpretaçóes díspares sobre esse conjunto de princípios em diferentes períodos.

$\mathrm{Na}$ primeira seção, ensaiamos consideraçóes sobre engajamento das tropas internacionais sob a gramática dos estudos da estratégia militar. Ao re- cuperar as relaçóes entre as deliberações políticas e o emprego dos instrumentos da violência, compreendemos que o engajamento de operaçóes de paz em contextos de conflitos assimétricos aproxima as estratégias empregadas pelo componente militar desse tipo de missão às doutrinas de pacificação.

Em sequência, dispomo-nos a explorar brevemente a evolução cronológica da concepção da organização em relação aos limites ao recurso a meios coercitivos em operaçóes de paz. Em síntese, insistimos na observação de uma tendência ao robustecimento das missóes de paz. Componentes militares autorizados a empregar meios coercitivos para o cumprimento do mandato ou para a proteçáo de civis passam a ser concebidos como alternativa para deter atores considerados espólios do projeto internacional de paz, e progressivamente tendem a açóes de engajamento ofensivo.

Por fim, debruçamo-nos sobre as recomendações listadas no relatório Improving Security of United Nations Peacekeeper. O texto de referência busca analisar as estatísticas de mortes de soldados internacionais e prescrever recomendaçóes à ONU. Compreendemos que o documento sugere tencionar a limitação do recurso a meios coercitivos a últimas instâncias, consolidando a atuaçáo de contingentes militares sob a flâmula da ONU em estratégias de orientação ofensiva.

\section{Um breve ensaio sobre Estratégia e Operaçōes de Paz}

$\mathrm{O}$ engajamento de tropas internacionais em intervençôes internacionais é informado por um conjunto de objetivos políticos que não se limita à resolução de conflitos ou ao alívio das violações de direitos e liberdades fundamentais (ORFORD, 2003; FOX, 2008). Para além dos objetivos manifestos de interromper a violência e garantir estabilidade na agenda de segurança internacional, as 
operaçóes de paz frequentemente empreendem reformas em instituições estatais, sobretudo centradas na democratização dos regimes políticos e liberalização econômica (RICHMOND, 2014).

Ao recuperar os interesses políticos que fundamentam a ação e o exercício estratégico mobilizado pelas operaçóes de paz da ONU é possível recordar as iniciativas de intervenção movidas pelas potências internacionais em diferentes contextos, concentradas no objetivo de promover a pacificação de um conflito (CUNLIFFE, 2012; MORENO, 2011). Ressalvamos que a identificação de pontos de intersecção entre diferentes iniciativas intervenientes não implica uma equivalência imediata das operaçóes de paz da ONU e outras formas de intervenção militar. Não propomos, portanto, uma alegoria excessivamente reducionista para aproximar modelos díspares de intervençōes militares e reconhecemos a demanda por análises que incorporem as especificidades de cada uma.

Contudo, compreendemos que observar essas tendências permite considerar alternativas críticas ao robustecimento das operaçóes de paz. Nesse sentido, Friis (2010, p. 50) enumera seis tendências convergentes entre a ação militar em operações de paz e as doutrinas de pacificação: o foco em atividades civis em detrimento das soluçôes exclusivamente militares; a ênfase na necessidade de proteger as populaçóes locais; a demanda por coerência entre diferentes atores em uma mesma abordagem; a atribuição de importância à participação dos grupos locais nas atividades mobilizadas através da intervenção; a relevância das açóes de inteligência; o reconhecimento de limites para o emprego de meios coercitivos em prol da satisfação do objetivo político. Neste breve trabalho, nos interessam especialmente o estatuto político da ação e as intersecçôes entre as atividades civis e militares na reprodução do resultado almejado por essas intervençóes.
Ao estudar o recurso a instrumentos bélicos pelos componentes militares das operaçóes de paz da ONU, convém reconhecer a interpretação sui generis da organização em relação aos níveis da ação militar. A demarcação entre as esferas estratégica, operacional e tática é vinculada predominantemente à estrutura de tomada de decisão da instituição (PEACE OPERATIONS TRAINING INSTITUTE, 2010). Em sua proposta, determina-se uma pirâmide em que o nível estratégico corresponde às decisões aprovadas pelo CSNU, as decisóes operacionais recaem sob a responsabilidade do quartel-general da missão em questão e as escolhas táticas são tomadas pelos comandantes dos componentes civil, policial ou militar (UNITED NATIONS, 2008). É apropriado indicar que a distribuição dos níveis de ação na proposta engendrada pela organizaçáo compreende zonas de intersecção entre os graus hierárquicos, como demonstramos na Figura 1.

O léxico apresentado pretende afastar a deliberação política do terreno, e sugere um processo decisório informado pela necessidade de atender a demandas humanitárias da agenda de Segurança Internacional e um engajamento caracterizado pela tecnicidade da atuação dos contingentes desdobrados em campo. Com efeito, o recurso a meios coercitivos é frequentemente apresentado sob o caráter da necessidade de interromper a resistência ao projeto de paz internacional e defender grupos ameaçados pela violência (UNITED NATIONS, 1995; 2000; 2008; 2015). Em agravo, as publicaçōes da ONU com referência a açôes políticas para a resolução de um conflito armado pretendem distancia-las das atividades militares (UNITED NATIONS, 2015). Compreendemos que essa categorização implica uma tentativa distorcida de confinar o recurso a instrumentos bélicos ao nível tático, distanciando-o das condicionantes políticas que orientam primordialmente a mobilizaçáo de tropas para operaçôes de paz. 
Figura 1 - Níveis da ação militar em uma Operação de Paz da ONU

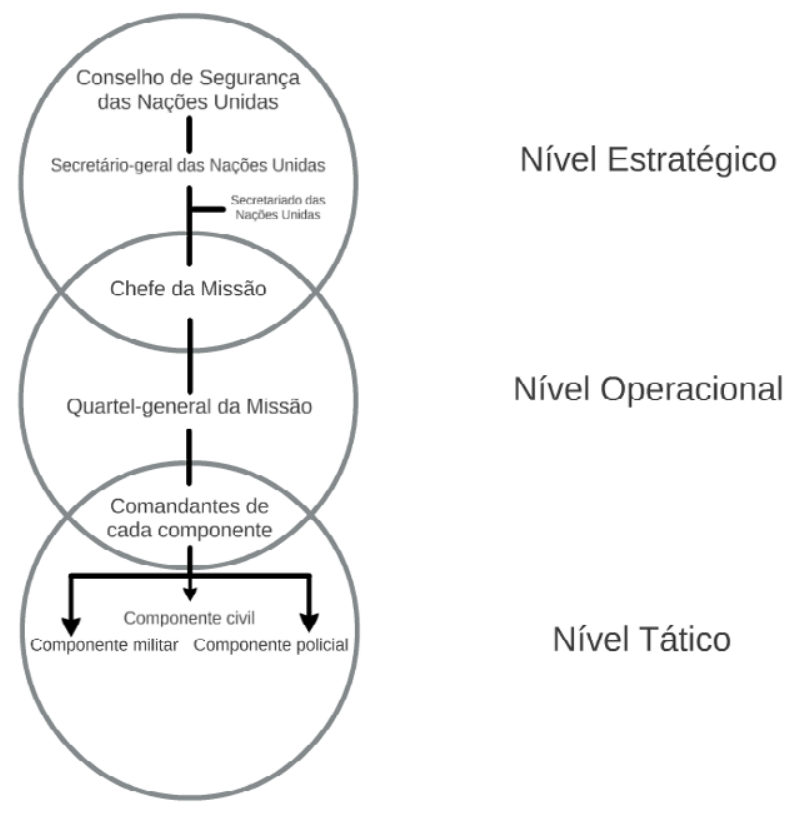

Fonte: Elaborado pelos autores a partir de PEACE OPERATIONS TRAINING INSTITUTE (2010).

Nesse sentido, Galula (2006) indica que as operaçóes militares em um conflito assimétrico são inescapavelmente políticas diante do objetivo de adquirir o apoio popular ou manter a população minimamente submissa ao ator interveniente. É prudente indicar que a assimetria que caracteriza esses conflitos não se limita às capacidades bélicas das partes. O caráter assimétrico se estende também através dos objetivos políticos, dos fundamentos ideológicos e das demandas que movem o conflito.

Não é suficiente para o governo determinar um conjunto de objetivos políticos, definir a intensidade da força militar aplicável, ingressar em alianças ou rompê-las; a política se torna um instrumento ativo das operaçôes. A associação entre as açōes militares e políticas é tão intricada que não podem ser facilmente apartadas; pelo contrário, todo movimento militar deve ser ponderado em relaçáo a seus efeitos políticos, e vice-versa (GALULA, 2006, p. 5, tradução nossa $\left.{ }^{4}\right)$.

\footnotetext{
4. Do original em inglês: "It is not enough for the government to set political goals, to determine how much military force is applicable, to enter into alliances or to break them; politics becomes an active instrument of operation. And so intricate is the interplay between the political and the military actions that they cannot
}

O engajamento militar é compreendido como um instrumento para a vitória em um conflito armado assimétrico. A aquisição do apoio da população consiste em objetivo último para a reprodução da ordem pretendida em campanhas de pacificação (GALULA, 2006; KILCULLEN, 2006; TRINQUIER, 2006). De maneira semelhante, as operaçóes de paz contemporâneas, demandam a incorporação de agentes locais em diferentes projetos mobilizados pelos atores intervenientes. Borges e Maschietto (2014) assinalam que as iniciativas para a inclusão de atores locais são predefinidas pelos atores externos e contribuem para a reprodução de uma agenda política e econômica liberal, representada nas temáticas de manutençâo de um regime democrático, de garantia de um conjunto de direitos e liberdades convencionados como fundamentais e do estabelecimento de relaçôes produtivas pautadas pela ideia de livre mercado.

be tidily separated; on the contrary, every military move has to be weighed with regard to its political effects, and vice versa" (GALULA, 2006, p. 5). 
Nesse sentido, as atividades da esfera tradicional de segurança são necessárias à implementação de iniciativas de provisão de auxílio humanitário e reforma das instituiçóes locais de organização social, compreendidas como alternativa para consolidar o apoio popular às forças intervenientes. Muito embora as operações de paz contemporâneas sejam concebidas sob a possibilidade de promover açóes de auxílio humanitário e reformas institucionais desde o início de sua mobilização, é adequado assinalar a precedência do desdobramento de funçóes de segurança, necessárias às atividades de escopo predominantemente civil.

Atividades de policiamento ostensivo pelas tropas intervenientes foram largamente documentadas entre as campanhas de pacificação, promovendo o controle da populaçáo local e exercendo funções políticas (GALULA, 2006; KILCULLEN, 2006). O contato com a populaçáo local e o desempenho de açôes de policiamento ostensivo também podem ser observados entre as atividades realizadas pelos componentes militares de operações de paz. Essas funçôes remetem ao objetivo de estender o exercício da autoridade dos atores governantes sobre o território sob intervenção. É possível traçar similaridades entre a práxis de pacificação e as açóes militares desenvolvidas pelos contingentes de operaçóes de paz. Em primeira instância, o caráter primordialmente político das campanhas; em sequência, a busca pelo apoio, ou submissão, da população local para a reprodução de uma ordem pretendida pelos atores intervenientes; e a prevalência de açóes que remetem às atividades de patrulhamento ostensivo.

$\mathrm{Na}$ seção seguinte, nos debruçamos sobre a reinterpretação dos princípios que orientam a aprovação de operaçóes e possibilitam uma postura progressivamente mais ofensiva para a atuação das tropas internacionais sob a bandeira da ONU. Para tanto, recuperamos documentos da organização que permitem traçar uma cronologia das interpre- tações da instituição sobre esses princípios. Em nossa discussão, enfatizamos as alteraçóes na concepção dos limites ao uso da força em uma operação.

\section{O uso da força em Operações de Paz: da Autodefesa ao Cumprimento do Mandato}

As operações de paz aprovadas pelo CSNU, apesar de não previstas na Carta de São Francisco, tornaram-se instrumento relevante e recorrente para o engajamento dos Estados-membros da ONU em iniciativas internacionais de promoção da paz. Tradicionalmente, os mandatos das operaçóes foram formulados de acordo com três princípios fundamentais: a necessidade de consentimento expresso pelo Estado sob intervenção; a imparcialidade da intervenção em relação aos beligerantes; e a restrição do uso da força a situações de autodefesa (BIGATÁO, 2014). Ao recuperar as operaçóes aprovadas entre 1948 e 1989, identificamos uma limitação bastante rígida do uso da força à autodefesa (KENKEL, 2013; BIGATÁO, 2014). É prudente indicar que a interpretação predominante da restrição do uso da força à autodefesa não implicou completa inação dos componentes militares das operaçóes de paz destacadas no mesmo período. Com efeito, ocorreram casos de engajamento militar significativos de missóes como a Operação das Naçóes Unidas no Congo (ONUC) ou a Força de Manutenção da Paz das Nações Unidas no Chipre (UNFICYP).

A partir da década de 1990 é possível observar um movimento de flexibilização da interpretação da tríade de princípios, sob a justificativa da necessidade de adequar as respostas internacionais às características contemporâneas do teatro de operaçóes das operaçôes de paz. Convém reconhecer que o processo de reforma dessas operações é constituído por um movimento polifônico que envolve diferen- 
tes instâncias no desenho organizacional da ONU (BIGATÃO, 2016). Entre as vozes predominantes destacamos: o Departamento de Operaçôes de Paz, os membros permanentes do CSNU, o Secretário-geral e os secretários especializados, o Comitê Especial sobre Operações de Manutenção da Paz. Para além dos componentes do desenho institucional, indicamos ainda o papel dos Estados responsáveis pela contribuição de recursos humanos, materiais e financeiros para as missóes.

Os graves obstáculos enfrentados pelas operações mobilizadas no período posterior a 1989 podem ser identificados como uma das causas para o movimento de reforma. As experiências negativas no engajamento da organização nos conflitos na Somália, em Ruanda e na Bósnia-Herzegovina foram determinantes para as discussóes em torno do processo de reforma dos modelos de intervenção. A incapacidade das missões em garantir a proteção da população civil e interromper manifestaçóes volumosas de violência foram interpretadas como indicativos da necessidade de mobilizar operaçôes dotadas dos recursos adequados para alcançar os objetivos almejados (UNITED NATIONS, 2000; KENKEL, 2013). É prudente indicar, no entanto, que os esforços iniciais de reforma precederam, ou ocorreram simultaneamente, à mobilização dessas operaçōes.

Com efeito, os textos de Uma Agenda para a Paz (UNITED NATIONS, 1992) e seu Suplemento (UNITED NATIONS, 1995) indicaram a necessidade de adequar as iniciativas para a paz às alteraçóes na agenda de segurança internacional. A primeira publicação ocorreu em um contexto de razoável expectativa quanto à possibilidade do destacamento de medidas coletivas para solucionar crises de segurança internacional. $\mathrm{O}$ texto, redigido pelo então Secretário-geral das Naçôes Unidas, Boutros Boutros-Ghali, inovou ao delinear tipologias para diferentes alternativas de engajamento da organização e de seus Estados-membros (UNITED
NATIONS, 1992). No documento estão listadas: a diplomacia preventiva, a promoção de paz, a manutenção da paz, e a consolidação da paz (UNITED NATIONS, 1992). Posteriormente, o texto suplementar incluiu a modalidade de imposiçáo da paz (UNITED NATIONS, 1995).

Nota-se que, apesar do indicativo da necessidade de robustecer o engajamento da organização nas crises de segurança que passam a ser abordadas a partir da década de 1990, o uso de meios coercitivos permaneceu limitado a casos excepcionais e os componentes militares não eram autorizados a impedir a atuação de grupos armados ou a impor as atividades necessárias para concluir os objetivos do mandato de uma operação (UNITED NATIONS, 1995). Nesse sentido, a postura das operaçóes aprovadas em consonância com essa interpretação permaneceu defensiva e reativa às volições de outras partes beligerantes, muito embora tenha incorporado a necessidade de prover segurança às populaçôes civis.

Em 1999, dois documentos elaborados pela ONU expuseram os limites da atuação de operaçôes destacadas para Ruanda e para a Bósnia-Herzegovina: no relatório "The Fall of Srebrenica", admitiu-se a necessidade de empregar todos os meios necessários para evitar a perseguição e o massacre de civis em zonas de conflito; e no relatório referente ao genocídio em Ruanda enfatizou-se a necessidade de revisar os princípios tradicionais das missões de paz em favor da proteção das populaçóes civis afetadas por um conflito armado (BIGATÃO, 2016; UNITED NATIONS, 1999a, 1999b).

É apropriado indicar que a publicação do Relatório Brahimi em 2000 propôs uma conversão das operaçôes de paz da ONU a ações mais incisivas em resposta aos desafios identificados ao longo da década anterior. O documento pavimentou as discussóes posteriores sobre operaçôes de paz. Sob o objetivo de ampliar resultados positivos das intervenções conduzidas sob o signo das 
Nações Unidas, no documento sugeriu-se a necessidade de adequar a atuação dos componentes mobilizados ao teatro de operaçóes contemporâneo (UNITED NATIONS, 2000). Em agravo, a reinterpretação da tríade de princípios possibilitou a ação de tropas internacionais contra grupos resistentes ao projeto de paz e mesmo a mobilização de intervençóes a despeito da inexistência de consentimento expresso pelas principais partes beligerantes. Conjugando de maneira coerente a reinterpretação dos dois primeiros princípios, admite-se o recurso a meios coercitivos para garantir o sucesso da intervenção na consecução dos objetivos definidos pelo CSNU.

Convém ressaltar que, apesar da ampliação das prerrogativas para o uso da força, os documentos oficiais revestiram a reinterpretaçáo da tríade de princípios com uma postura defensiva, explicitada na proteção de civis e na garantia de execução do mandato aprovado para a missão. No entanto, os debates institucionais sobre a reforma das operaçóes de paz enfatizaram a necessidade de engajamento proativo, e por vezes antecipado, dos componentes militares. Insistimos que essa interpretação ignora a prevalência de objetivos políticos que orientam a aprovação de mandatos para novas operaçóes e o desembarque de tropas internacionais em sociedades sob intervenção.

A publicação da Doutrina Capstone em 2008 cristalizou uma posição favorável ao recurso a instrumentos bélicos para garantir o sucesso dos objetivos políticos e estratégicos da intervenção. $\mathrm{O}$ documento acrescentou textualmente a "defesa do mandato" à redação do princípio de restrição do uso da força pelas tropas internacionais (UNITED NATIONS, 2008, p. 31). Como resultado, publicaçôes institucionais subsequentes admitiram a possibilidade do uso da força para garantir a conclusão de objetivos políticos descritos no mandato das missóes (PEACE OPERATIONS
TRAINING INSTITUTE, 2010; UNITED NATIONS, 2015).

Ao transportar a análise para os mandatos originais das missóes aprovadas ao longo das décadas de 2000 e 2010, observamos a recorrência da autorização sob o Capítulo VII da Carta de São Francisco. Das dezoito operaçóes aprovadas pelo CSNU no período, treze continham menção à possibilidade do recurso a meios coercitivos, ora constrito à proteçấo de civis, ora abrangendo a implementação de outros objetivos do mandato (UNITED NATIONS SECURITY COUNCIL, 2018). No Quadro 1, listamos os objetivos desempenhados pelos componentes militares ou policiais dessas missóes com previsão para o uso da força.

É apropriado interpretar que os documentos de reforma dos princípios que regem a aprovação de novas operações de paz da ONU produziram reflexos sobre o desdobramento das missões. Sem prejuízo à tendência identificada, é possível observar missões que mantém intensidades de engajamento militar concentradas nas tarefas tradicionais de autodefesa e monitoração das beligerâncias. Nesse sentido, assinalamos que, enquanto os documentos doutrinários imprimem tendências quanto ao recurso à coerção em operaçóes de paz, o regimento específico de cada missão é determinado pelas Regras de Engajamento, no caso dos componentes militares, ou pelas Diretrizes para o Uso da Força, direcionadas aos componentes policiais. Acrescentamos que essas regras específicas podem ser reeditadas de acordo com a identificação de novas necessidades estratégicas em terreno.

A seguir debruçamo-nos sobre as recomendações mais recentes em relação às operações militares desdobradas pelas operaçóes de paz da ONU. Em um contexto desafiador às inciativas de resoluçáo de conflitos, o robustecimento das operaçóes foi apresentado como alternativa para solucionar crises contemporâneas. 


\section{Quadro 1 - Marndatos com menção ao Capítulo VII da}

Corta de São Froncisco (2000-2018)

\begin{tabular}{|c|c|c|}
\hline Nome da Missão & $\begin{array}{c}\text { Resoluçáo e } \\
\text { ano }\end{array}$ & Características do uso da força \\
\hline $\begin{array}{l}\text { United Nations Mission of } \\
\text { Support in East Timor (UN- } \\
\text { MISET) }\end{array}$ & $1410(2002)$ & Cumprimento do mandato. \\
\hline $\begin{array}{l}\text { United Nations Mission in } \\
\text { Liberia (UNMIL) }\end{array}$ & $1509(2003)$ & $\begin{array}{c}\text { Manutenção da lei e da ordem; implementaçáo do acordo } \\
\text { de cessar-fogo. }\end{array}$ \\
\hline $\begin{array}{l}\text { United Nations Operation in } \\
\text { Côte d'Ivoire (UNOCI) }\end{array}$ & $1528(2004)$ & Cumprimento do mandato. \\
\hline $\begin{array}{l}\text { United Nations Stabiliza- } \\
\text { tion Mission in Haiti (MI- } \\
\text { NUSTAH) }\end{array}$ & $1542(2004)$ & $\begin{array}{l}\text { Garantia de um ambiente seguro e estável; ajuda no mon- } \\
\text { itoramento, reestruturaçáo e reforma da Polícia Nacional; } \\
\text { auxíliar em programas de desarmamento, desmobilização } \\
\text { e reintegração; ajuda com a restauraçáo e manutenção do } \\
\text { estado de direito, segurança e ordem pública; proteção dos } \\
\text { funcionários das Naçóes Unidas e de civis sob ameaça imi- } \\
\text { nente de violência física. }\end{array}$ \\
\hline $\begin{array}{l}\text { United Nations Operation in } \\
\text { Burundi (ONUB) }\end{array}$ & $1545(2004)$ & Cumprimento do mandato. \\
\hline $\begin{array}{l}\text { United Nations Mission in } \\
\text { Sudan (UNMIS) }\end{array}$ & $1590(2005)$ & $\begin{array}{l}\text { Proteção dos funcionários das Naçóes Unidas, tra- } \\
\text { balhadores humanitários e civis. }\end{array}$ \\
\hline $\begin{array}{l}\text { AU/UN Hybrid operation in } \\
\text { Darfur (UNAMID) }\end{array}$ & $1769(2007)$ & $\begin{array}{l}\text { Proteção dos funcionários das Naçóes Unidas, tra- } \\
\text { balhadores humanitários e civis; cumprimento do mandato. }\end{array}$ \\
\hline $\begin{array}{l}\text { United Nations Organization } \\
\text { Stabilization Mission in the } \\
\text { Democratic Republic of the } \\
\text { Congo (MONUSCO) }\end{array}$ & $1925(2010)$ & Cumprimento do mandato e proteção a civis. \\
\hline $\begin{array}{l}\text { United Nations Interim Securi- } \\
\text { ty Force for Abyei (UNISFA) }\end{array}$ & $1990(2011)$ & $\begin{array}{c}\text { Proteção dos funcionários das Nações Unidas, tra- } \\
\text { balhadores humanitários e civis; proteção da área de } \\
\text { incursóes por elementos não autorizados e garantia da se- } \\
\text { gurança. }\end{array}$ \\
\hline $\begin{array}{l}\text { United Nations Mission in the } \\
\text { Republic of South Sudan (UN- } \\
\text { MISS) }\end{array}$ & $1996(2011)$ & $\begin{array}{l}\text { Cumprimento do mandato; assistência ao Governo da } \\
\text { República do Sudão do Sul no cumprimento de sua re- } \\
\text { sponsabilidade de proteger os civis; reduzir a violência, } \\
\text { inclusive por meio de patrulhamento em áreas de alto risco } \\
\text { de conflito, protegendo civis sob ameaça iminente de vi- } \\
\text { olência física; proteção dos funcionários das Naçóes Unidas } \\
\text { e de trabalhadores humanitários. }\end{array}$ \\
\hline $\begin{array}{l}\text { United Nations Multidimen- } \\
\text { sional Integrated Stabilization } \\
\text { Mission in Mali (MINUSMA) }\end{array}$ & $2100(2013)$ & $\begin{array}{l}\text { Cumprimento do mandato; estabilização dos principais } \\
\text { centros populacionais e apoio ao restabelecimento da au- } \\
\text { toridade do Estado; proteção dos funcionários das Naçóes } \\
\text { Unidas e de civis; apoio à assistência humanitária. }\end{array}$ \\
\hline $\begin{array}{l}\text { United Nations Multidimen- } \\
\text { sional Integrated Stabilization } \\
\text { Mission in the Central African } \\
\text { Republic (MINUSCA) }\end{array}$ & $2149(2014)$ & Cumprimento do mandato; proteção de civis. \\
\hline $\begin{array}{l}\text { United Nations Mission for Jus- } \\
\text { tice Support in Haiti (MINU- } \\
\text { JUSTH) }\end{array}$ & $2350(2017)$ & $\begin{array}{l}\text { Cumprimento do mandato; proteçáa de civis sob ameaça } \\
\text { iminente de violência física. }\end{array}$ \\
\hline
\end{tabular}




\section{A Ofensiva Militar revestida de Autodefesa}

Sob o lema "ninguém ataca um oponente mais forte", o texto de referência Improving Security of United Nations Peacekeepers 5 esboçou consideraçôes em relação às mortes de soldados internacionais atuando em operaçóes de paz no quinquênio 2013-2017. Entre 2013 e 2017, de acordo com o United Nations Operations and Crisis Centre (2018), 180 soldados de componentes militares de operaçóes de paz foram mortos em decorrência de atos hostis. Entre as prescrições contidas no texto, destacamos a ênfase na necessidade de ampliar a liberdade de ação dos contingentes internacionais através de uma postura ofensiva, frequentemente exposta como uma atitude "proativa" ou "preemptiva" em relação às demais partes beligerantes (SANTOS CRUZ; PHILIPS; CUSIMANO, 2017). De acordo com Santos Cruz, Philips e Cusimano: "infelizmente, as forças hostis não entendem uma linguagem diferente da força. Para deter e repelir ataques e derrotar os atacantes, as Naçôes Unidas precisam ser fortes e não temer usar a força quando necessário" (2017, p. 7, tradução nossa ${ }^{6}$ ).

Nesse sentido, é adequado afirmar que, progressivamente, o engajamento de componentes militares de operaçóes de paz se aproxima da ação de Exércitos regulares em outros conflitos armados, ao prever, inclusive, a possibilidade de combate aberto com as demais partes beligerantes:

A mentalidade adequada é especialmente importante em relaçáo ao uso da força. Em condiçôes normais, de baixo risco (por exemplo, demonstraçóes civis), o uso de força "proporcional” é um conceito sólido. Entretanto, em

5. O relatório é produto de uma pesquisa de campo financiada pelo governo da República Popular da China através do United Nations Peace and Development Trust Fund.

6. Do original, em inglês: "unfortunately, hostile forces do not understand a language other than force. To deter and repel attacks and to defeat attackers, the United Nations needs to be strong and not fear to use force when necessary". ambientes de alto risco, onde as ferramentas da oposiçáo incluem emboscada, ataque terrorista e combate aberto, as Naçóes Unidas devem empregar uma força esmagadora. Se tais confrontos náo forem vencidos pelas $\mathrm{Na}$ çôes Unidas, os funcionários morrem (SANTOS CRUZ; PHILIPS; CUSIMANO, 2017, p. 12, tradução nossa ${ }^{7}$, grifo nosso).

É plausível indicar que o documento apresentou uma descrição mais detalhada das recomendações de aplicação militar do que seus antecessores. No entanto, as prescriçóes que orientam uma postura mais ofensiva são revestidas sob matizes de autodefesa, sobretudo orientadas pelo objetivo de fornecer uma capacidade ampliada às operaçóes em proteger as pontas de lança do componente militar. A propositura é vacilante, ora ao indicar a necessidade de empregar meios militares sobejos, ora ao retornar aos princípios que orientam a aprovação de novos mandatos para operações de paz.

As recomendaçóes aproximam-se das prescriçôes das doutrinas militares de pacificação ao enfatizar a necessidade de deter a iniciativa na campanha, a consolidação de áreas seguras, a realização de patrulhas ostensivas constantes, a manutenção do contato com a população civil, e a ênfase nas atividades de inteligência (SANTOS CRUZ; PHILIPS; CUSIMANO, 2017). A aquisição do consenso da população civil demanda atenção ímpar ao ser considerado denominador necessário para a reprodução da ordem pretendida pelos atores intervenientes.

Em agravo, o relatório ignorou as implicaçóes de uma postura mais muscular dos componentes militares, sobretudo em relação à população que é afetada cotidianamente pelas manifestaçóes de violência (DIGOLIN, 2018). Apenas como exercício

7. Do original, em inglês: "The proper mindset is especially important regarding the use of force. Under normal, lower risk conditions (e.g. civil demonstrations) the use of "proportional" force is a sound concept. However, in higher-risk environments, where opposition's tools include ambush, terrorist attack, and open combat, the United Nations must employ overwhelming force. If such confrontations are not won by the United Nations, personnel die". 
exploratório, é possível ensaiar possíveis implicações negativas de prerrogativas mais amplas para o recurso a meios coercitivos: violaçóes de direitos e liberdades fundamentais, açóes excessivamente truculentas e a morte de civis em meio às campanhas militares.

Hunt (2016, p. 115) sintetiza seis áreas que podem ser negativamente impactadas pelo uso progressivamente mais robusto da força por operaçóes de paz: a vulnerabilidade de civis; a segurança dos funcionários das Naçôes Unidas; o acesso de fluxos de auxílio humanitário; a garantia de direitos e liberdades fundamentais; os processos de desenvolvimento e consolidação da paz após o conflito e os prospectos de um processo político de paz. É possível observar outras implicações de ações mais robustas de uma operação de paz: a perda, ou percepçáo de perda, da imparcialidade da missão, a intensificação do conflito e a percepção dos atores locais da violação da soberania nacional (TARDY, 2011, p. 162).

Apesar de negligenciar os prospectos negativos das recomendaçôes do relatório em relação ao recurso mais robusto a meios coercitivos, a ONU sugeriu o acolhimento de prescriçóes significativas do texto de referência (UNITED NATIONS, 2018). Assinalamos que as possibilidades de implicaçóes negativas do emprego mais intensivo de meios coercitivos e da adoção de uma postura ofensiva diante do quadro de segurança de uma operação de paz tendem a dirimir as possibilidades da consolidação de uma conjuntura pacífica positiva.

\section{Considerações Finais}

Compreendemos que, no decorrer das discussōes acerca da revisão de reforma das operaçōes de paz, é adequado identificar uma reinterpretação substantiva dos princípios que tradicionalmente orientaram a redação e aprovação de mandatos para essas missóes. Nesse ínterim, destacamos a possibi- lidade de engajamento militar mais intenso pelos componentes de operaçóes de paz da ONU, sobretudo ao tornar mais elásticas as prerrogativas para o recurso a meios coercitivos. Outrora limitado à defesa dos componentes e instalações de uma missão de paz, a violência torna-se instrumento para a proteção de civis e a conclusão de objetivos políticos descritos pelo mandato aprovado pelo CSNU.

Insistimos que as iniciativas de intervenção internacional contemporâneas não são integralmente originais, visto que remetem às campanhas militares de pacificação de outrora. O inescapável conteúdo político das açóes militares em operaçóes de paz e a demanda pela participaçấo das populaçóes locais através de estruturas gestadas de maneira impositiva são sensivelmente necessários para a reprodução dos resultados almejados através da intervenção.

Adicionalmente, a transformação no tradicional princípio restritivo permite às operaçóes de paz vislumbrar uma ampliação da liberdade de ação militar. O recurso a meios coercitivos permite aos componentes militares atuarem com postura ofensiva de maneira a sustentar os objetivos políticos e estratégicos da ação. Ao atuar sob característica antecipada, os componentes militares das operaçóes aproximam-se das táticas de eliminação e expulsão de adversários em conflitos assimétricos. Nesse sentido, a vitória militar precede as iniciativas de reformas econômicas, políticas e sociais que permitem adquirir o apoio da população sob intervenção, necessário para a consolidação do resultado.

Em agravo, é possível identificar que as discussóes institucionais sobre o recurso ao instrumento militar frequentemente ignoram as implicações negativas que uma postura ofensiva pode gerar sobre o processo de paz. É adequado assinalar que as intervenções sob viés humanitário ocultam a reprodução de uma ordem injusta e exploradora, frequentemente associada às contribuiçóes políticas de atores internacionais. As implicações se esten- 
dem por sobre a percepçáo dos atores locais quanto às beligerâncias e podem impactar negativamente a proteção das populaçôes civis e à consolidação de uma conjuntura pacífica, justa e emancipatória. Nesse sentido, faz-se necessário considerar alternativas para soluçấo de crises de segurança internacional que transcendam o recurso recorrente à violência como instrumento para a imposição da paz.

\section{Referências Bibliográficass}

BIGATÃO, J. P. A norma de proteção das Operaçôes de Paz da ONU: os mandatos robustos da década de 2000. Conjuntura Global, Curitiba, v. 5, n. 3, p. 460-483, set./dez. 2016. Disponível em: <https://revistas.ufpr.br/conjgloblal/article/ view/50541>. Acesso em: 25 abr. 2019.

BIGATÃO, J. P. Operações de paz da ONU: a década de 1990 e a crise de responsabilidades. In: MATIJASCIC, V. B. (Org.). Operaçóes de manutençáo de paz das Naçóes Unidas: reflexôes e debates. São Paulo: Ed. UNESP, 2014.

BORGES, M.; MASCHIETTO, R. H. Cidadania e empoderamento local em contextos de consolidação da paz. Revista Crítica de Ciências Sociais, Coimbra, n. 105, p. 65-84, dez. 2014. Disponível em: <https://journals.openedition.org/ rccs/5800>. Acesso em: 25 abr. 2019.

CUNLIFFE, P. Still the spectre at the feast: comparisons between Peacekeeping and Imperialism in Peacekeeping Studies today. International Peacekeeping, v. 19, n. 4, p. 426-442, aug. 2012. Disponível em: <https://www.tandfonline.com/doi/full/1 0.1080/13533312.2012.709751>. Acesso em: 25 abr. 2019.

DIGOLIN, K. A. Setenta anos de operaçóes de paz da ONU: balanço histórico e atuais desafios. Eris - Defesa e Segurança Internacional, [s.l.], 05 jul. 2018. Disponível em: <http:// www.eris-gedes.org/single-post/2018/07/05/Setenta-anos-de-opera\%C3\%A7\%C3\%B5es-de-paz-da-ONU-balan\%C3\%A7o-hist\%C3\%B3rico-e-atuais-desafios-1>. Acesso em: 20 jul. 2018.

FOX, G. H. Humanitarian occupation. Cambridge: Cambridge University Press, 2008.

FRIIS, K. Peacekeeping and counter-insurgency - two of a kind? International Peacekeeping, v. 17, n. 1, p. 49-66, feb. 2010. Disponível em: <https://www.tandfonline.com/doi/ful 1/10.1080/13533311003589199>. Acesso em: 25 abr. 2019.

GALULA, D. Counterinsurgency warfare: theory and practice. Westport, London: Praeger Security International, 2006.

HUNT, C. T. All necessary means to what ends? The unintended consequences of the 'robust turn' in UN peace operations. International peacekeeping, v. 24, n. 1, p. 108-131, 2016.
Disponível em: <https://www.tandfonline.com/doi/full/10.10 80/13533312.2016.1214074>. Acesso em: 25 abr. 2019.

KENKEL, K. M. Five generations of peace operations: from the "thin blue line" to "painting a country blue". Revista Brasileira de Política Internacional, Rio de Janeiro, v. 56, n. 1, p. 122-143, 2013. Disponível em: $<$ http://www.scielo.br/scielo.php?script=sci_arttext\&pi$\mathrm{d}=$ S0034-73292013000100007\&lng=en\&nrm=iso >. Acesso em: 25 abr. 2019.

KILCULLEN, D. Twenty-eight articles: fundamentals of company-level counterinsurgency. IO Sphere, p. 29-35, Summer 2006. Disponível em: <http://www.au.af.mil/info-ops/iosphere/iosphere_summer06_kilcullen.pdf>. Acesso em: 25 abr. 2019.

MORENO, M. F. A herança colonial das "novas" operaçóes de paz da ONU. Revista Ética e Filosofia Política, Juiz de Fora, v. 2, n. 12, p. 70-90, jul. 2011. Disponível em: <http://ojs2. ufj.emnuvens.com.br/eticaefilosofia/article/view/17770>. Acesso em: 25 abr. 2019.

ORFORD, A. Reading Humanitarian Intervention: human rights and the use of force in international law. Cambridge: Cambridge University Press, 2003.

PEACE OPERATIONS TRAINING INSTITUTE. Principles and guidelines for UN Peacekepping Operations. Williamsburg: Peace Operations Training Institute, 2010.

RICHMOND, O. P. Failed Statebuilding: intervention and the dynamics of peace formation. New Haven: Yale University Press, 2014

SANTOS CRUZ, C. A.; PHILIPS, W. R.; CUSIMANO, S. Improving Security of United Nations Peacekeepers: we need to change the way we are doing business. [S.l: s.n.], 2017. Disponível em: <https://peacekeeping.un.org/sites/default/ files/improving_security_of_united_nations_peacekeepers_report.pdf>. Acesso em: 19 jul. 2018.

TARDY, T. A critique of robust peacekeeping in contemporary peace operations. International Peacekeeping, v. 18, n. 2, p. 152-167, apr. 2011. Disponível em: <https://www.tandfonline.com/doi/full/10.1080/13533312.2011.546089>. Acesso em: 25 abr. 2019.

TRINQUIER, R. Modern Warfare: a French view of counterinsurgency. Westport, London: Praeger Security International, 2006.

UNITED NATIONS. An agenda for Peace: preventive dilomacy, peacemaking and peacekeeping. A/47/277-S/24111. 17 jun. 1992. Disponível em: <http://www.un.org/en/ga/search/ view_doc.asp?symbol=A/47/277>. Acesso em: 13 jul. 2018.

UNITED NATIONS. Improving Security of United Nations Peacekeepers Action Plan for Implementation of Fatalities Report. 09 apr. 2018. Disponível em: <https://peacekeeping.un.org/sites/default/files/180406_action_plan_revised.pdf>. Acesso em: 20 jul. 2018. 
UNITED NATIONS. Report of the Panel on United Nations Peace Operations. A/55/305-S/2000/809. 21 aug. 2000. Disponível em: <https://documents-dds-ny.un.org/doc/ UNDOC/GEN/N00/594/70/pdf/N0059470.pdf?OpenElement>. Acesso em: 09 dez. 2018.

UNITED NATIONS. Report of the Secretary-General pursuant to General Assembly resolution 53/35: The Fall of Srebrenica. A/54/549. 15 nov. 1999b. Disponível em: <https:// documents-dds-ny.un.org/doc/UNDOC/GEN/N99/348/76/ img/N9934876.pdf?OpenElement>. Acesso em: 01 mar. 2019.

UNITED NATIONS. Supplement to an Agenda for Peace: position paper of the Secretary-general on the occasion of the fiftieth anniversary of the United Nations. A/50/60-S/1995/1. 25 jan. 1995. Disponível em: <https://documents-dds-ny. un.org/doc/UNDOC/GEN/N95/080/95/pdf/N9508095.pdf?OpenElement>. Acesso em: 03 dez. 2018.

UNITED NATIONS. United Nations Peacekeeping Operations: principle and guidelines. New York: United Nations, 2008. Disponível em: <http://www.un.org/en/peacekeeping/ documents/capstone_eng.pdf $>$. Acesso em: 16 jul. 2018.

UNITED NATIONS. Uniting our strengths for peace: politics, partnership and people: report of the High-level Independent Panel on United Nations Peace Operations. A/70/ 95-S/2015/446. 17 jun. 2015. Disponível em: <http://www. un.org/en/ga/search/view_doc.asp?symbol=S/2015/446>. Acesso em: 16 de jul. de 2018.

UNITED NATIONS. Report of the Independent Inquiry into the actions of the United Nations during the 1994 genocide in Rwanda. S/1999/1257. 16 dec.1999a. Disponível em: <http://www.un.org/en/ga/search/view_doc.asp?symbol=S/1999/1257>. Acesso em: 01 mar. 2019.

UNITED NATIONS OPERATIONS AND CRISIS CENTRE. Fatalities by Mission and Incident Type. 2018. Disponível em: <https://peacekeeping.un.org/sites/default/files/statsbymissionincidenttype_4_15.pdf>. Acesso em: 16 jul. 2018.

UNITED NATIONS SECURITY COUNCIL RESOLUTIONS. Latest resolutions. 2018. Disponível em: <http:// unscr.com>. Acesso em: 19 jul. 2018.

UNITED NATIONS SECURITY COUNCIL. Security Council Resolutions. 2018. Disponível em: <http://www. un.org/en/sc/documents/resolutions/>. Acesso em: 19 jul. 2018. 